\title{
Processing Eucalyptus cloeziana seed lots to improve purity, germination and vigor
}

\author{
Thomas Bruno Michelon ${ }^{1 *} \oplus$, Elisa Serra Negra Vieira ${ }^{2}$, Maristela Panobianco ${ }^{1} \odot$
}

\author{
1Universidade Federal do Paraná - Depto. de Fitotecnia e \\ Fitossanidade, R. dos Funcionários, 1540 - 80035-050 - \\ Curitiba, PR - Brasil. \\ ${ }^{2}$ Embrapa Florestas, Estrada da Ribeira, km 111 - 83411- \\ 000 - Colombo, PR - Brasil. \\ *Corresponding author <thomasbrunomichelon@gmail.com>
}

Edited by: Jason J. James

Received November 11, 2019

Accepted January 16, 2020

\begin{abstract}
Eucalyptus cloeziana is one of the highest-density wood species offering significant added value, frequently used in the construction and furniture industries. Despite its suitability, it may be overlooked on account of its propagation difficulties due either to its low rooting cutting capacity or to its seeds having a low germination rate perhaps attributable to the high proportion of indistinguishable impurities within the seed lots. This study aimed to develop an efficient technique for Eucalyptus cloeziana seed processing to increase the physical purity and, consequently, the physiological quality of the seed lot. Three seed lots, separated by size in sieves with $1.18,1.00$, and $0.84 \mathrm{~mm}$ square openings, were used. X-ray analyses were carried out, the number of normal seedlings and germination rate identified and the percentage and speed of seedling emergence under greenhouse conditions ascertained. The greenhouse evaluation showed that the seed retained in the $1.18 \mathrm{~mm}$ sieve presented viability and vigor twice that of the control. Therefore, the processing technique by size classification is efficient in terms of improving the physical and physiological performance of Eucalyptus cloeziana seed lots.

Keywords: eucalypt, physical purity, emergence, seedlings
\end{abstract}

\section{Introduction}

The wood of the Eucalyptus cloeziana is highdensity due to its high carbon fixation, surpassing other species of the same genus commonly used in forest cultivation, such as E. grandis and E. urophylla (Chen et al., 2010; Li et al., 2017). This characteristic makes it the traditional choice for the energy production industry, and its wood is extremely strong and durable. Consequently, it is often used in construction, post construction, railway sleepers, and high value-added products, found in the furniture industry (Atyeo et al., 2008; Boland et al., 2006; Clarke et al., 2009). This species has been mentioned within the genus Eucalyptus as a means of income diversification, especially for small producers (Santarosa et al., 2014).

Eucalyptus is the most cultivated forest genus in Brazil, but, despite its interesting characteristics, $E$. cloeziana is little used. The reason for this is related to reproductive difficulties, as the traditional form of propagation of Eucalyptus by cloning is not viable due to the low rooting capacity of cuttings (Tormen et al., 2018), while its seeds have a lower germination rate than other species of the same genus despite being produced in large quantities. In recognition of these phenomena, several authors (Clarke et al., 2009; Erickson et al., 2016) have suggested that this low germination characteristic may not be related to possible low seed quality, but rather to the high proportion of indistinguishable seed impurities within the seed lots post-harvest. For certain specific species of Eucalyptus, impurities may represent up to $90 \%$ of all material (Clark et al., 2010). Impurities can be easily separated from seeds of other larger-seed eucalyptus species, such as E. globulus and E. amygdalina (Clark et al., 2010), but it is not possible in E. cloeziana due to the small size and color of the seeds.
On the other hand, undesirable contaminants such as immature seeds and inert material can be removed by the processing operation, which has the purpose of separating impurities from pure seeds based on differences of physical characteristics between seeds and impurities, and thus contribute to improving the seed lot quality. Therefore, this study aimed to develop an efficient technique for Eucalyptus cloeziana seed processing to increase the physical purity and, consequently, the germination potential of the seed lot.

\section{Materials and Methods}

Three Eucalyptus cloeziana seed lots, produced in Antônio João (Mato Grosso do Sul, Brazil), were used. Figure 1 shows one of the E. cloeziana seed lots, detailing difficulties when visually identifying and differentiating impurities from seeds.

The processing activities were carried out in a laboratory located in Curitiba, PR, Brazil. Each seed lot was initially homogenized by a riffle splitter, and seeds were separated by size through sieves with 1.18 , 1.00 , and $0.84 \mathrm{~mm}$ square openings; seeds retained in these three sieves were collected. Each fraction was homogenized and reduced again to obtain an average sample with a minimum weight of $40 \mathrm{~g}$ (MAPA, 2009) which, subsequently, constituted the working sample.

\section{The following were determined:}

\section{X-ray test:}

Processed and non-processed seeds were analyzed in an X-ray machine to confirm correct separation of seeds from impurities, as well as identifying the ideal anatomical seed characteristics of the seeds to differentiate them from inert material. This determination was performed 


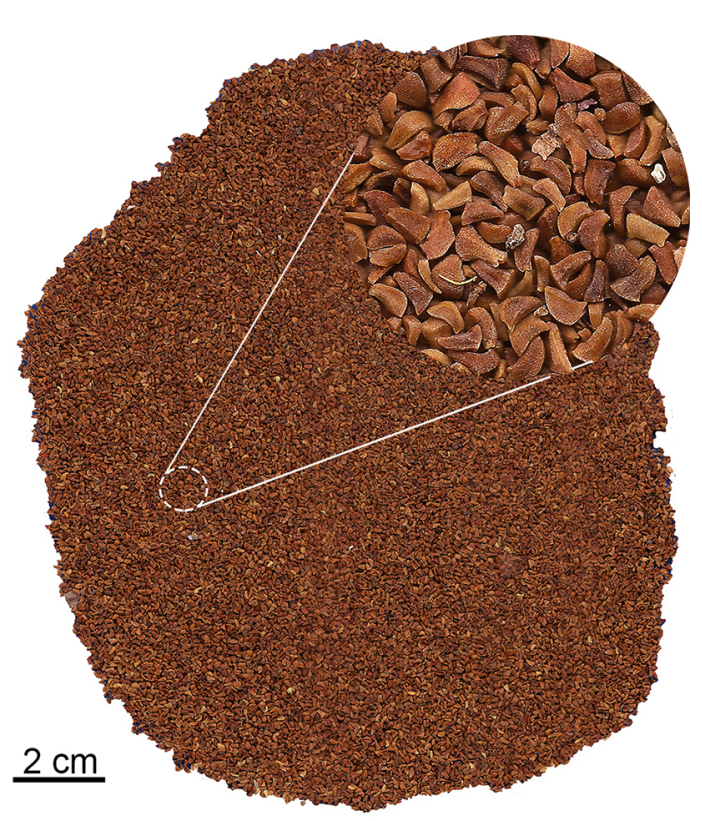

Figure 1 - Representation of one of the non-processed Eucalyptus cloeziana seed lots. The detail illustrates the impossibility of visual distinction between impurities and seeds.

in a laboratory located in Lavras, MG, Brazil, by using a Faxitron HP 43855AX X-ray machine automatically calibrated to $35 \mathrm{Kv}$ exposure intensity for $17.7 \mathrm{~s}$. A total of 200 seeds were used per treatment, divided into four replications of 50 seeds each and fixed in acetate sheet using transparent double-sided adhesive tape. Digital radiographic images were analyzed on a computer, and individual seeds were identified as filled or empty.

\section{Germination:}

Processed samples were placed accordingly to germinate, divided into four subsamples of $0.5 \mathrm{~g}$ (statistical replications), and sown on the sand in plastic boxes $(11.0 \times 11.0 \times 3.5 \mathrm{~cm})$. The sand substrate was sieved to obtain medium particle size material (less than $1.00 \mathrm{~mm}$ and greater than $0.1 \mathrm{~mm})$. Subsequently, sand was autoclaved at $200{ }^{\circ} \mathrm{C}$ for $60 \mathrm{~min}$.

The substrate was moistened with $20 \mathrm{~mL}$ of water, equivalent to $50 \%$ of the substrate retention capacity. These boxes were placed in a Mangelsdorf germinator set at $25{ }^{\circ} \mathrm{C}$, under continuous light. The first and final counts were performed at 14 and 21 days after sowing, respectively (MAPA, 2009). Results were expressed as the number of normal seedlings per $\mathrm{kg}$ of seeds.

At the same time, daily evaluations were made during the germination test from the identification of the first normal seedling until germination stabilization. The germination speed index (GSI) was calculated using the Maguire (1962) equation:

$$
G S I=\frac{G_{1}}{N_{1}}+\frac{G_{2}}{N_{2}} \cdots+\frac{G_{n}}{N_{n}},
$$

where $G_{1}+G_{2}+G_{n}$ refers to the number of germinated seeds observed from the first to the final count and $N_{1}$ $+N_{2}+N_{n}$ refers to the number of days elapsed from sowing to first, second, and the final count, respectively.

The design used for germination evaluations was completely randomized in a $4 \times 3$ factorial scheme, with four replications. The first factor was related to processing $(\mathrm{T}=$ control/no processing, and sieve coded as follows: $\mathrm{P} 1.18=1.18 \mathrm{~mm}$ opening, $\mathrm{P} 1.0=1.00 \mathrm{~mm}$ opening, and P0.84 $=0.84 \mathrm{~mm}$ opening), while the second factor was related to the lot (L1, L2, and L3), making a total of 48 experimental units.

\section{Seedling emergence:}

This test was carried out in a greenhouse located in Colombo, PR, Brazil $\left(25^{\circ} 19^{\prime} \mathrm{S}, 49^{\circ} 09^{\prime} \mathrm{W}\right.$, altitude of $1027 \mathrm{~m}$ ) using seeds retained in sieves with1.18 and $1.00 \mathrm{~mm}$ openings and sown in $110 \mathrm{~cm}^{3}$ tubes with commercial substrate composed of: sphagnum peat, expanded vermiculite, carbonized rice husk, dolomitic limestone, agricultural gypsum, NPK fertilizer, and micronutrients. Planting fertilization consisted of the application of $0.6 \mathrm{~kg} \mathrm{~m}^{-3}$ of ammonium sulfate, $4 \mathrm{~kg}$ $\mathrm{m}^{-3}$ of single superphosphate, $0.2 \mathrm{~kg} \mathrm{~m}^{-3}$ of potassium chloride, and $1.5 \mathrm{~kg} \mathrm{~m}^{-3}$ of FTE BR 10, as recommended by Kratz (2017). Mist irrigation was carried out four times a day, once in the morning and three times in the afternoon, with each watering period lasting $10 \mathrm{~min}$..

The speed of seedling emergence (ESI) was reported duri ng the emergence test in a greenhouse, with daily evaluations made from the emergence of the first normal seedling to emergence stabilization. The ESI was calculated using the Maguire (1962) equation:

$E S I=\frac{E_{1}}{N_{1}}+\frac{E_{2}}{N_{2}} \cdots+\frac{E_{n}}{N_{n}}$,

where $E_{1}+E_{2}+E_{n}$ refers to the number of normal seedlings observed from the first to the final count and $N_{1}+N_{2}+N_{n}$ refers to the number of days elapsed from sowing to the first, second, and the final count, respectively. When the evaluations were made, data pertaining to the percentage of seedling emergence were also computed.

The design used in the emergence studies was completely randomized in a $3 \times 3$ factorial scheme, with five replications of 10 tubes with six seeds each. The first factor consisted of the processing $(\mathrm{T}=$ control/no processing, sieves had different size openings as follows: $\mathrm{P} 1.18=1.18 \mathrm{~mm}$ opening sieve, and $\mathrm{P} 1.0=1.00 \mathrm{~mm}$ opening sieve), and the second factor was the lots (L1, L2, and L3).

Statistical analysis was based on the use of generalized linear models (GLM), in which each response (frequency of filled seeds, germinated seeds, GSI, percentage and speed of seedling emergence) was evaluated under different distributions according to the data characteristics to obtain the best fit model and, consequently, higher inference quality. The adequacy 
of the models for the data was evaluated according to the Akaike information criterion and Schwarz Bayesian criterion (Olsson, 2002), where the lowest indices represent models with a better fit.

The normal distribution was tested on all data, in which the number of normal seedlings and frequency of filled seeds were compared with Poisson and negative binomial distributions. A binomial distribution was used on the percentage of emerged seedlings, while the gamma distribution was used for the germination and emergence speed indices.

A Poisson distribution was used for the number of normal seedlings and frequency of filled seeds since it was the best fit, represented by

$f(y ; \mu)=\frac{\mu^{y} e^{-\mu}}{y !}$,

where $y$ is the number of normal seedlings and $\mu$ the mean of normal seedlings. The GSI was analyzed based on the gamma distribution:

$f(y ; \mu, V)=\frac{\left(\frac{v}{\mu}\right)^{v}}{\Gamma(\nu)} y^{\nu-1} \exp \left\{\frac{y v}{\mu}\right\}$,

where $y$ is the number of normal seedlings, $\mu$ the mean of normal seedlings, and $v$ the variance function. The percentage of emergence and ESI for the most appropriate distribution was the normal where:

$f\left(y ; \mu, \sigma^{2}\right)=\frac{1}{\sqrt{2 \pi \sigma^{2}}} \exp \left[-\frac{1}{2} \frac{(y-\mu)^{2}}{\sigma}\right]$

The Tukey test was used for a comparison of means considering a significance level of 0.05. All the analyses were carried out using the R software program, version 3.5.2.

\section{Results and Discussion}

The X-ray analysis carried out on lot 2 (Figure 2A-D) showed the presence of filled (with opaque white inner part surrounded by a dark line) and nonfertilized/empty seeds (darker and translucent) in all tested fractions $(\mathrm{P} 1.18=1.18 \mathrm{~mm}, \mathrm{P} 1=<1.18 \mathrm{~mm}$ and $>1.00 \mathrm{~mm}, \mathrm{P} 0.84=<0.84 \mathrm{~mm}$, and $\mathrm{T}=$ control/ no processing). Therefore, E. cloeziana-filled seeds could not be visually distinguished from the others either by shape or by size.

Figure 3 shows that in lots 1 and 2, the control (T) and the material lower than $0.84 \mathrm{~mm}$ (P0.84) had the lowest frequencies of filled seeds, while the material retained in the sieve with the $1.18 \mathrm{~mm}$ opening (P1.18) had the highest proportion of filled seeds compared to those that were empty.

The frequency of filled seeds in lot 3 (Figure 3) did not differ statistically between sieves, possibly because this lot had a lower physical quality when compared to
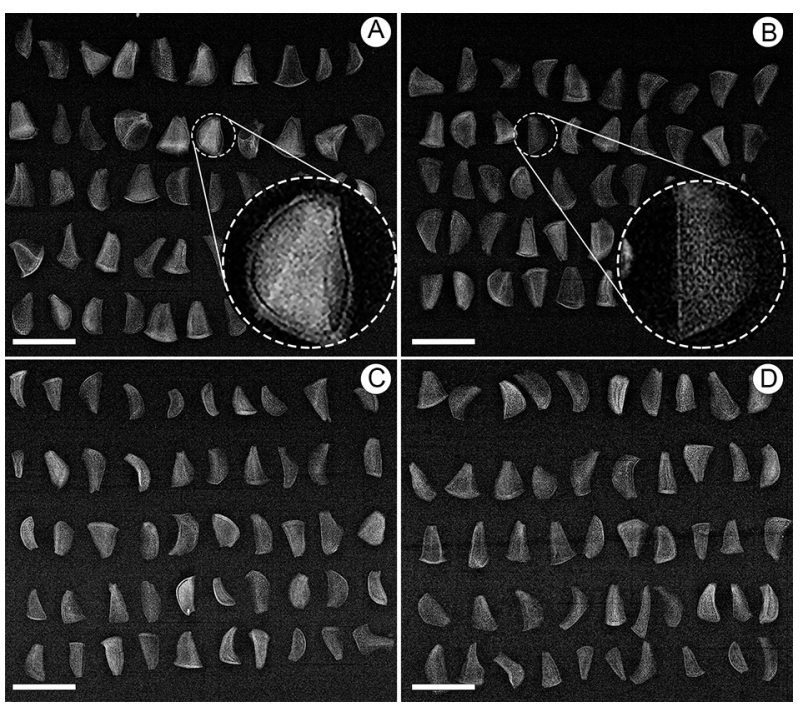

Figure 2 - X-ray analysis of lot 2 for the different separated fractions of Eucalyptus cloeziana: greater than $1.18 \mathrm{~mm}(\mathrm{~A})$, between 1.18 and $1 \mathrm{~mm}(\mathrm{~B})$, lower than $0.84 \mathrm{~mm}(\mathrm{C})$, and control (D). Magnification in A detailing the characteristics of a seed considered filled. Magnification in B detailing the characteristics of a seed considered empty. Bars represent a $2 \mathrm{~mm}$ scale.

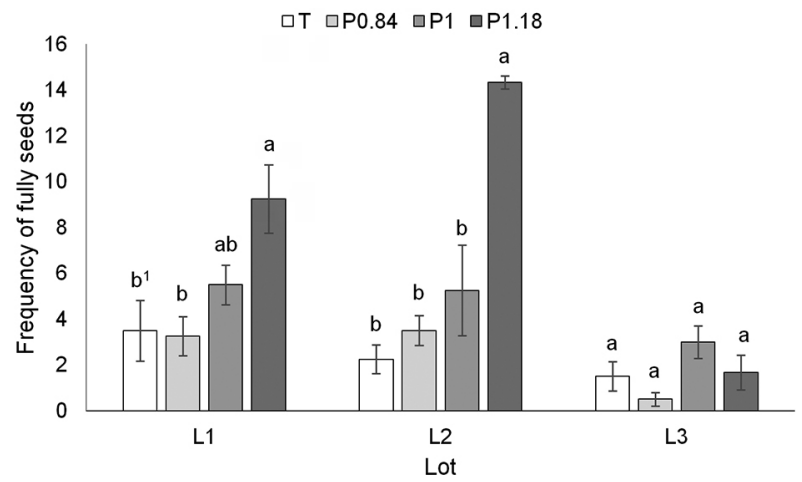

Figure 3 - Frequency of filled seeds observed in the X-ray analysis of processed and non-processed Eucalyptus cloeziana seeds from three lots. $T=$ control; sieve openings coded as follows: P1.18 $=1.18 \mathrm{~mm} ; \mathrm{P} 1.0=1.00 \mathrm{~mm}$, and P0.84 $=0.84 \mathrm{~mm}$ where ${ }^{1} p<0.05$.

the others; the limited amount of seed used for the X-ray evaluation was not sufficient to express the difference observed in the other sieves. Eucalyptus gumnut have viable seeds and unfertilized ovules (Chaff); the proportion, according to Boland et al. (2006) can vary according to climatic factors, abiotic stresses, and the physiological characteristics of each plant; these factors may have contributed to the variation observed in the lots.

For the three lots, the material retained in 1.18 (P1.18) and $1.00 \mathrm{~mm}$ (P1) sieve openings provided a significant increase in the number of normal seedlings obtained in the germination test (Figure 4). In this case, the sieve with the largest opening (1.18) yielded the best result, with an average of approximately three times 


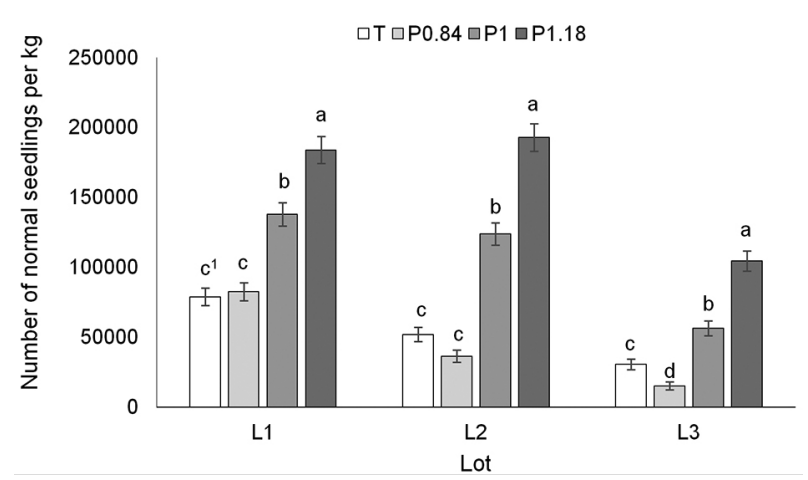

Figure 4 - Number of normal seedlings per $\mathrm{kg}$ of processed and non-processed Eucalyptus cloeziana seeds from three lots. $T=$ control; sieve openings coded as follows: P1.18 = $1.18 \mathrm{~mm}$; P1.0 $=1.00 \mathrm{~mm}$, and P0.84 $=0.84 \mathrm{~mm}$ where ${ }^{1} p<0.05$.

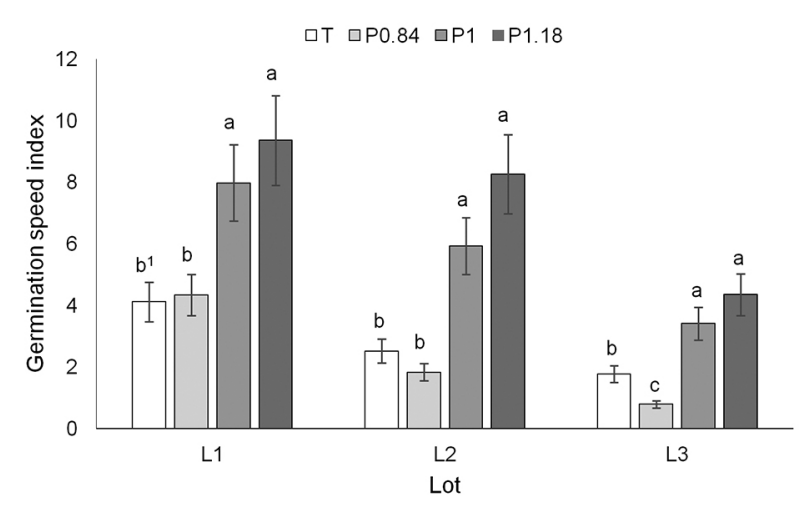

Figure $\mathbf{5}$ - Speed of germination index of processed and nonprocessed Eucalyptus cloeziana seeds from three lots. $\mathrm{T}=$ control; sieve openings coded as follows: P1.18 = $1.18 \mathrm{~mm}$; P1.0 $=1.00 \mathrm{~mm}$, and P0.84 $=0.84 \mathrm{~mm}$ where ${ }^{1} p<0.05$.

more normal seedlings than the control. In contrast, the material smaller than $0.84 \mathrm{~mm}$ (P0.84) was statistically similar to the control in lots 1 and 2, and lower than the control in lot 3.

The excessive proportion of impurities (empty seeds and inert material) within the seed lots usually creates difficulties in management practices for seedling production since this species is mainly propagated by seeds (Clarke et al., 2009). Excess impurities require the use of a large amount of material, generating variation in the number of seedlings emerged per container and increasing production costs in commercial nurseries, due to increases in the transplanting and thinning practices.

The increased number of normal seedlings obtained after the processing operation can be attributed in particular to the increased proportion of pure seeds (Larios et al., 2014; Paz et al., 2005; Wang et al., 2017) after the separation of impurities.

As in the present study, the use of sieves was effective in reducing the quantity of inert materials in Eucalyptus maculata seed lots (Silva et al., 1994). It was reported that the material retained in sieves with 2.0 and $1.68 \mathrm{~mm}$ openings showed values of 92 and $97 \%$ of pure seeds, respectively, while the fraction traversing the smallest sieve opening $(1.19 \mathrm{~mm})$ presented a value of only $0.9 \%$, and most of the impurities consisted of non-fertilized ovules.

As for seed vigor, the speed of germination (Figure 5) demonstrated that the use of seeds retained in 1.00 (P1) and $1.18 \mathrm{~mm}(\mathrm{P} 1.18)$ sieve openings provided a 2 to 3 fold increase in the germination rate when compared to those of the control ( $\mathrm{T})$.

As regards the results obtained in the greenhouse (Figure 6), E. cloeziana seeds larger than $1.18 \mathrm{~mm}$ had a significant increase compared to the control (double), both in the number of seedlings per tube and in the speed of seedling emergence, with the control showing only $29 \%$ emergence of normal seedlings and 0.262 of ESI, not statistically differet from seeds retained in the $1.00 \mathrm{~mm}$ opening sieve. This result was similar to the germination data obtained in the laboratory that demonstrated the effectiveness of using a $1.18 \mathrm{~mm}$ sieve opening, in which seeds were not only more likely to produce a normal seedling but also spent less time on it.

Mao et al. (2019) considered seed size as being one of the most important characteristics in the production of Pinus thunbergii seedlings since larger seeds have higher survival rates, as a consequence of their higher soluble sugar content, mainly affecting seed vigor (Ambika et al., 2014). In addition, as in the present study, Naidu and Jones (2007) used E. grandis and E. smithii seeds and computed seedling emergence of up to $50 \%$ more in the nursery, from seeds classified as large (>1.00 $\mathrm{mm}$ ) compared to those classified by the authors as small (between 0.5 and $0.71 \mathrm{~mm}$ ).

Since one of the obstacles to greater use of the Eucalyptus species is the difficulty of obtaining vigorous seedlings from seeds, the use of seeds of higher physiological quality favor the seedling production process which thereby reduce the barriers to $E$. cloeziana expansion.

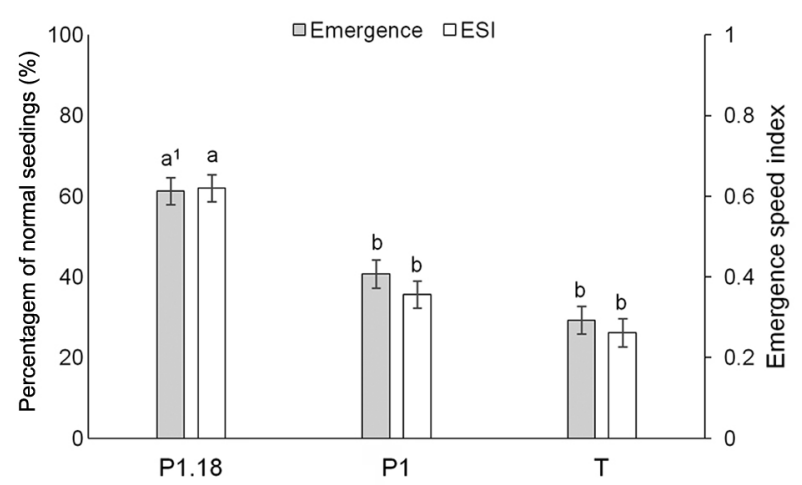

Figure 6 - Percentage and speed of seedling emergence of processed and non-processed Eucalyptus cloeziana seeds under greenhouse conditions. $\mathrm{T}=$ control; sieve openings coded as follows: $\mathrm{P} 1.18=1.18 \mathrm{~mm} ; \mathrm{P} 1.0=1.00 \mathrm{~mm}$ where ${ }^{1} p<0.05$. 
In the case of $E$. cloeziana, no studies addressing seed processing were found in the literature. Thus, the technique developed in the present study is promising due to its efficiency and ease of application and can be used by commercial nurseries and growers in general.

\section{Conclusions}

The processing technique using a $1.18 \mathrm{~mm}$ sieve opening gives the lot a higher physical purity and considerably increases the germination rate of $E$. cloeziana seeds.

The classification by size is efficient in terms of improving both the physical and physiological performance of Eucalyptus cloeziana seed lots.

\section{Acknowledgments}

The Coordination for the Improvement of Higher Level Personnel (CAPES) Foundation for granting the scholarship.

\section{Authors' Contributions}

Conceptualization: Panobianco, M.; Vieira, E.S.N. Data acquisition: Michelon, T.B.; Panobianco, M.; Vieira, E.S.N. Data analysis: Michelon, T.B. Design of methodology: Panobianco, M.; Vieira, E.S.N. Writing and editing: Michelon, T.B.; Panobianco, M.; Vieira, E.S.N.

\section{References}

Ambika, S.; Manonmani, V.; Somasundar, G. 2014. Review on effect of seed size on seedling vigour and seed yield. Research Journal of Seed Science 7: 31-38.

Atyeo, W.J.; McGavin, R.L.; Hopewell, G.P. 2008. Evaluation of Wood Characteristics of Tropical Post-Mid-Rotation Plantation Eucalyptus cloeziana and E. pellita: Part (d) Veneer and Plywood Potential. FWPA, Melbourne, Australia.

Boland, D.; Brooker, M.; Chippendale, G.; Hall, N.; Hyland, B.; Johnston, R.; Kleining, A.; McDonald, W.; Turner, J. 2006. Forest Trees of Australia. CSIRO, Melbourne, Australia.

Chen, S.X.; Wu, Z.H.; Li, Z.H.; Xie, Y.J.; Li, T.H.; Zhou, Q.Y.; Arnold, R. 2010. Selection of species for solid wood production in southern China. Journal of Tropical Forest Science 22: 308316.

Clark, L.; Edwards, L.; Neyland, M. 2010. Eucalypt Seed and Sowing. Forestry Tasmania, Hobart, Australia. (Native Forest Silviculture Technical Bulletin, 1).

Clarke, B.; McLeod, I.; Vercoe, T. 2009. Trees for Farm Forestry. 22. Promising Species. Rural Industries Research and Development Corporation, Canberra, Australia.
Erickson, T.E.; Barrett, R.L.; Merrit, D.J.; Dixon, K.W. 2016. Pilbara seed atlas and field guide: plant restoration in Australia's arid northwest. CSIRO, Melbourne, Australia.

Kratz, D.; Nogueira, A.C.; Wendling, I.; Mellek, J.E. 2017. Physicchemical properties and substrate formulation for Eucalyptus seedlings production. Scientia Forestalis 45: 63-76.

Larios, E.; Búrquez, A.; Becerra, J.X.; Venable, D.L. 2014. Natural selection on seed size through the life cycle of a desert annual plant. Ecology 95: 3213-3220.

Li, C.; Weng, Q.; Chen, J.B.; Li, M.; Zhou, C.; Chen, S.; Zhou, W.; Guo, D.; Lu, C.; Chen, J.C.; Xiang, D.; Gan, S. 2017. Genetic parameters for growth and wood mechanical properties in Eucalyptus cloeziana F. Muell. New Forests 48: 33-49.

Maguire, J.D. 1962. Speed of Germination: aid in selection and evaluation for seedling emergence and vigor. Crop Science 2: 176-177.

Mao, P.; Guo, L.; Gao, Y.; Qi, L.; Cao, B. 2019. Effects of seed size and sand burial on germination and early growth of seedlings for coastal Pinus thunbergii Parl. in the Northern Shandong Peninsula, China. Forests 10: 281-295.

Ministério da Agricultura, Pecuária e Abastecimento [MAPA]. 2009. Rules for Seed Analysis = Regras para Análise de Sementes. MAPA, Brasília, DF, Brazil (in Portuguese).

Naidu, R.D.; Jones, N.B. 2007. Effect of seed size on field survival and growth of Eucalyptus in KwaZulu-Natal, South Africa. Southern Hemisphere Forestry Journal 69: 19-26.

Olsson, U. 2002. Generalized Linear Models: An Applied Approach. Studentlitteratur, Lund, Sweden.

Paz, H.; Mazer, S.J.; Martinez-Ramos, M. 2005. Comparative ecology of seed mass in Psychotria (Rubiaceae): within- and between-species effects of seed mass on early performance. Functional Ecology 19: 707-718.

Santarosa, E.; Penteado, J.F.; Goulart, I.C.G.R. 2014. Eucalyptus cultivation in rural properties: diversification of production and income $=$ Cultivo de eucalipto em propriedades rurais: diversificação da produção e renda. Embrapa Floresta, Colombo, PR, Brazil (in Portuguese).

Silva, A.; Kasai, F.S.; Castellani, E.D.; Aguiar, I.B.; Carvalho, N.M. 1994. Influence of size on Eucalyptus maculata Hook seed quality. Revista Brasileira de Sementes 16: 187-190 (in Portuguese, with abstract in English).

Tormen, G.C.R.; Figueiredo, A.J.R.; Santos Ribeiro, A.; Santos, L.F.; Araújo, J.F.; Brondani, G.E.; Silva, A.L.L. 2018. Carbohydrate sources, alanine and calcium for in vitro multiplication of Eucalyptus cloeziana F. Muell. Iheringia. Série Botânica 73: 329-335.

Wang, T.-T.; Chu, G.-M.; Jiang, P.; Niu, P.-X.; Wang, M. 2017. Effects of sand burial and seed size on seed germination, seedling emergence and seedling biomass of Anabasis aphylla. Pakistan Journal of Botany 49: 391-396. 